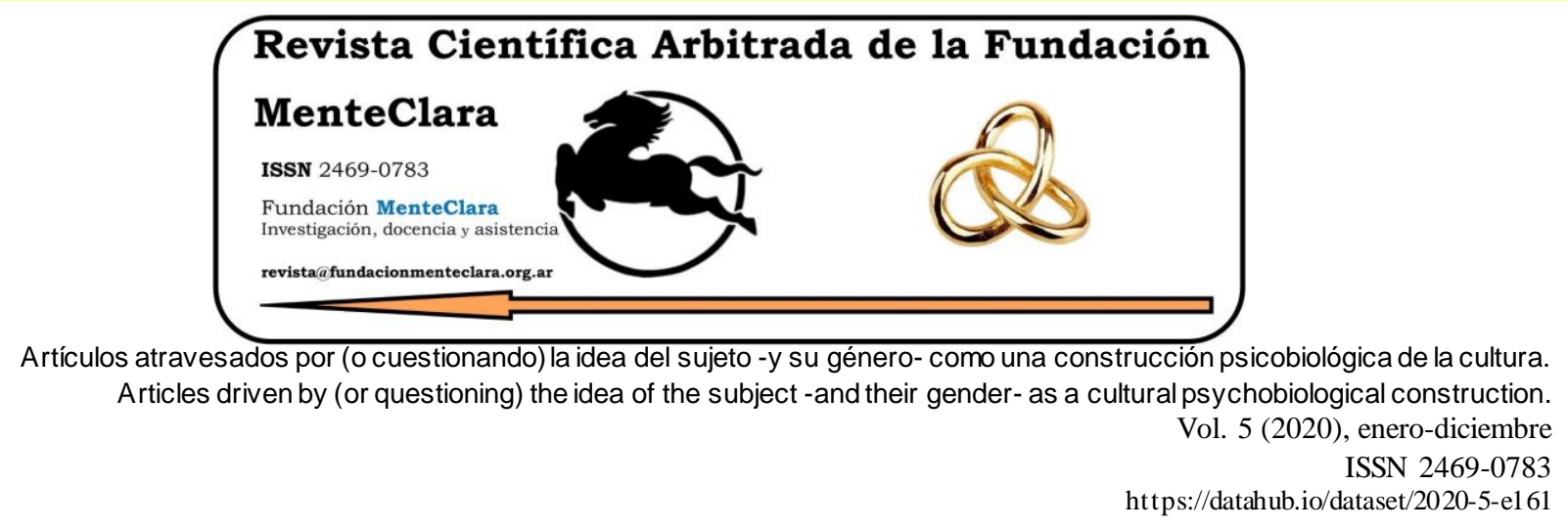

\title{
EL GRITO DE ALCORTA Y LA REALIDAD NACIONAL*
}

Jorge Francisco Cholvis jorgecholvis@yahoo.com.ar

Universidad Nacional de Lanús, Argentina

Cómo citar este artículo / Citation: Cholvis J. F. (2020). «El grito de Alcorta y la realidad nacional". Revista Científica Arbitrada de la Fundación MenteClara, Vol. 5 (154). DOI: https://doi.org/10.32351/rca.v5.161

Copyright: (C) 2020 RCAFMC. Este artículo de acceso abierto es distribuido bajo los términos de la licencia Creative Commons Attribution 4.0 International License (CC BY 4.0). Recibido: 16/06/2020. Publicación online: 17/06/2020

Conflicto de intereses: Ninguno que declarar.

* Publicado por primera vez en Redacción Popular, Información Alternativa para la Unidad Latinoamericana, 6 de abril de 2008. http/ /:www.redaccionpopular.com.ar; Revista Científica. Equipo Federal de1 Trabajo, Año III - N ${ }^{\circ} 36,4$ de mayo de 2008

Palabras Claves: Grito de Alcorta, luchas agrarias; Vicentin, oligarquía

\section{Introducción:}

Dadas las circunstancias del caso "VICENTIN", y la actitud que adoptan ahora los grupos hegemónicos -tanto económico-financieros, como mediáticos-, para oponerse a las politicas que impulsa el gobierno nacional al respecto, les presento la revisión de un texto que publiqué hace unos años y en el que trato de poner en evidencia una histórica lucha que se inició precisamente los días de junio en la Provincia de Santa $\mathrm{Fe}$, la que fue encabezada por quienes se encontraban afectados en el goce de sus derechos, por arcaicas e injustas invocaciones de concepciones jurídicas utilizadas por los sectores dominantes en las primeras décadas del siglo XX. 
Es que fue el 15 de junio de 1912, en la histórica plaza del pueblo llamado Bigand, de dicha provincia, cuando se produjo el inicial llamado a la huelga agraria declarada después el día 25 de junio de ese año, y que se conoce como "El Grito de Alcorta". Una lucha rural por mejorar las condiciones en que se encontraban los colonos, sujetos a leoninos contratos de arrendamiento y al pretendido derecho de propiedad que invocaban los arrendadores; es decir, los terratenientes, proclamando el "derecho absoluto de la propiedad privada", en su exclusivo beneficio.

Las reacciones que se promueven desde la denominada actualmente "oligarquía diversificada", contra dichas medidas que fueron adoptadas por el gobierno nacional, denotan que todavía se produce similar confrontación. Como señalamos en el artículo con palabras de Arturo Enrique Sampay, entendemos que en el caso que se trate de impulsar la idea de justicia oligárquica que aún la Constitución "real" tuviese como fin, y que de tal modo se quisiera invalidar la sanción de medidas dirigidas a mejorar las condiciones de vida del pueblo, "ello en puridad sería un acto de subversión contra el progreso de la Justicia".

De tal modo, ante lo que en estos tiempos ser observa con el desfalco de VICENTIN y las argumentaciones de los defensores del derecho absoluto de propiedad privada al confrontar con políticas públicas, marginar el rol del Estado y la presencia de los mayoritarios sectores populares en la producción y defensa de la Casa Común, me surge la necesidad de difundir nuevamente este texto; y asimismo, expresar con él, mi convencimiento que no es suficiente teorizar sobre los derechos y la justicia, sino que es necesario luchar para su efectivo logro y la felicidad de nuestro pueblo.

Castelar, Provincia de Buenos Aires, 15 de junio de 2020. Jorge Francisco Cholvis. 


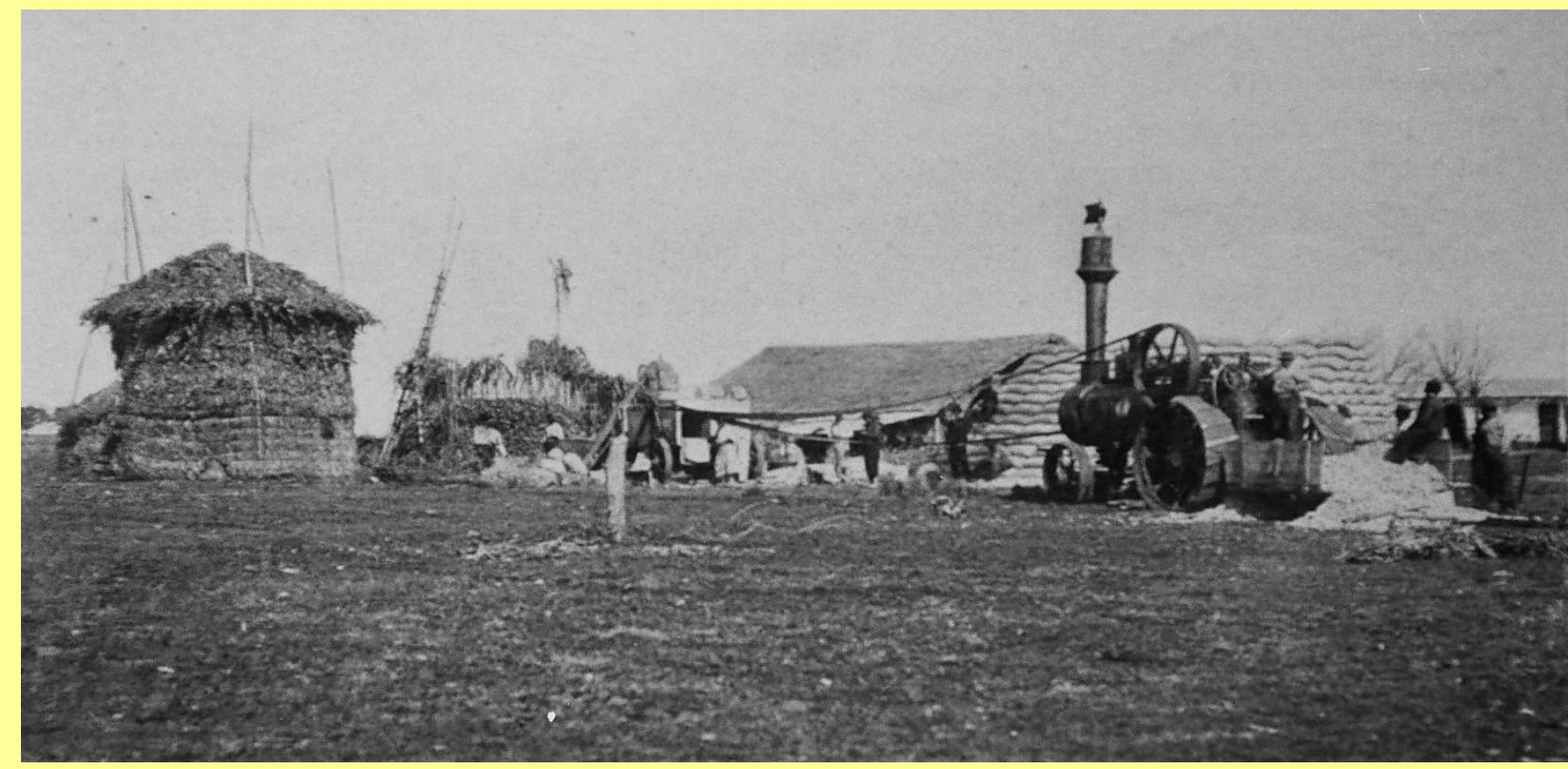

\section{El grito de Alcorta. Un hecho histórico que nos potencia en nuestro tiempo}

La población argentina se encuentra sometida actualmente a una delicada situación política, impulsada por un "lockoul" patronal desestabilizador de las instituciones, que no sólo desconoce la legitimidad democrática de los poderes de gobierno electos en recientes comicios, sino que además, por su decidida y diseñada metodología lleva al encarecimiento de numerosos recursos esenciales para la población y al total desabastecimiento de otros por lo que privan a los sectores mayoritarios de la población su comida diaria.

En los cortes, según parece, sólo dejarán pasar a camiones que transportan leche y lo promocionan como un "gesto" de buena voluntad; aunque la realidad es que a las vacas las tienen que ordeñar, porque las pobres con sus mugidos por el dolor de las ubres hinchadas les recordarán constantemente el delito que están cometiendo. Ya vimos torrentes de leche derramada que millones de chicos no pueden tomar y otros alimentos perecederos que se tuvieron que tirar.

Con las actitudes que asumen las corporaciones se han arrogado el rol de suplir el voto popular y confrontan con la legalidad y legitimidad del orden constitucional, y crean condiciones para un sombrío golpe de Estado como los que tenemos registrados en nuestra memoria. La historia de esta parte sur del continente americano tiene dos ejemplos célebres de lockout patronales con desabastecimiento, como parte principal de la escalada golpista: el de 1973 contra el gobierno de 
Salvador Allende en Chile, y el de 1976 en la Argentina contra Isabel Perón. Dicha postura sólo aparece motivada por su interés sectorial, aunque sobre él "se montan los pequeños grupos interesados en acabar con el gobierno que impulsó el castigo a los responsables de aquella dictadura, y que fijó la redistribución del ingreso como una meta central” (Horacio Verbitsky, “Acero inoxidable”, Página 12, 30 de marzo de 2008).

Para morigerar la reacción que producen las bravuconadas que se observan en los cortes y la intemperante actitud que ellas expresan, quieren ocultar la autoría de las consecuencias que indudablemente van a producir, y con ese objetivo pretenden desviar la atención y argumentan que es culpa del gobierno al haber resuelto aplicar retenciones móviles a las exportaciones de cereales -su preocupación fundamental es la que se aplica a la soja-, medida que sólo disminuye las extraordinarias ganancias que están recibiendo por los precios internacionales de esos "commodities".

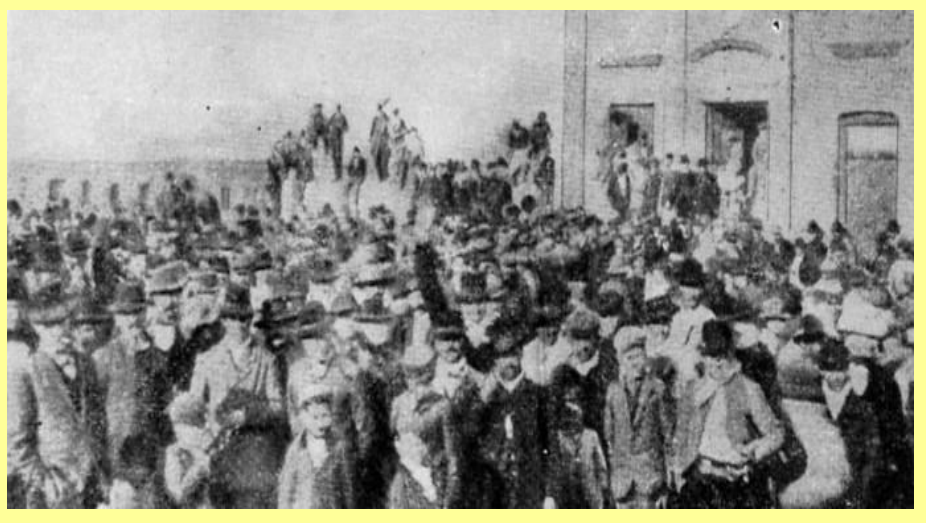

Asamblea de colonos en Alcorta-25 de Junio de 1912

En defensa de esta renta extraordinaria engañosas voces quieren traer en su apoyo, algunas batallas agrarias heroicas de verdad, como fue el "Grito de Alcorta". Bien señaló al respecto la Presidenta de la Nación que "cuando uno recuerda hay que recordar las historias completas" (discurso pronunciado en el encuentro de Parque Norte, el 27 de marzo de 2008).

Vamos a ver qué fue ese pronunciamiento de los colonos de Alcorta y de otras ciudades de Santa Fe, Buenos Aires, Córdoba y Entre Ríos, y si su lucha tiene alguna relación con los objetivos que actualmente impulsa el lockoutpatronal, con las graves secuelas que dejará a la población. 
El movimiento huelguista campesino estalló en Alcorta, Provincia de Santa Fe.

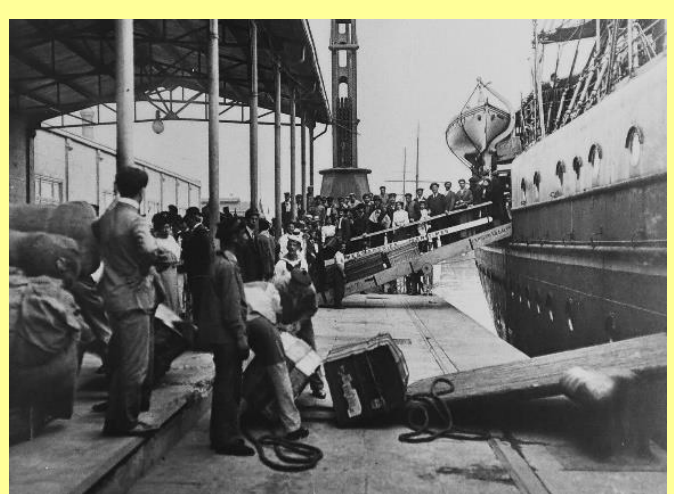

Era la más importante zona agrícola de la provincia y en ella estaban radicados cerca de 2.000 colonos, de los cuales 1500 eran italianos y 500 españoles. En Alcorta abundaban los colonos socialistas y anarquistas. No es secreto para nadie que conozca medianamente las características de

primeras migraciones argentinas, que nuestro país más que ningún otro, asimiló a obreros y agricultores revolucionarios que trajeron esas experiencias a estas tierras americanas. La mayor parte de los inmigrantes no tuvieron acceso a la propiedad de la tierra y debieron radicarse

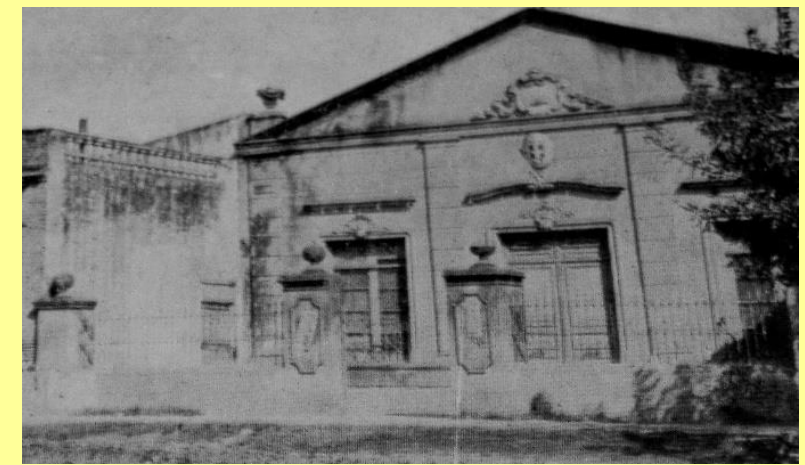

Sociedad Italiana donde se pronunciara el Grito de Alcorta el 25 de Junio de 1912 como arrendatarios en los distintos pueblos de la provincia. Los beneficios que producia la tierra no alcanzaron nunca a satisfacer ni medianamente las necesidades de los arrendatarios, muchos de los cuales dejaron hasta sus propias vidas sobre campos ajenos.

El 25 de junio de 1912, en la amplia sala de la Sociedad Italiana de Alcorta, los colonos pronunciaron el grito formidable que luego recorrió el vasto territorio de la República. Al poco tiempo la lucha se expandió, y los agricultores de las provincias de Santa Fe, Córdoba, Entre Ríos y Buenos Aires, iniciaron un proceso contra la oligarquía que movilizó a más de 120.000 trabajadores del agro argentino. Era su pelea por trabajar la tierra.

Muchos inmigrantes de los que estaban radicados en campos de esas provincias, tenian referencias o habian participado de las sublevaciones campesinas de Francia, Italia o Irlanda. Sin duda, los agricultores conocían la lucha que sostuvieron los irlandeses contra Inglaterra en los años 1870 a 1880. Si en 1910 se habían sublevado los campesinos de Macachín, en La Pampa, no tardó mucho tiempo en que la efervescencia llegara a las campiñas santafesinas donde los colonos sufrían una mayor explotación. 
Si bien la huelga la declararon los colonos de Alcorta, no es menos cierto, también, que ese acontecimiento fue una consecuencia de las actitudes decisivas que habían adoptado con anterioridad los chacareros de Firmat y Bigand. El primer manifiesto dirigido a los agricultores del país fue escrito por los dirigentes de la Sociedad Cosmopolita de Firmat. El inicial llamado a la huelga fue dado por los colonos de Bigand en la histórica asamblea realizada en la plaza de dicho pueblo el 15 de junio de 1912 .

Sin duda, "El Grito de Alcorta" está estrechamente vinculado a los importantes hechos sociales $y$ politicos que al comenzar el siglo $\mathrm{XX}$ sacudieron las bases del país. La lucha sindical comenzaba

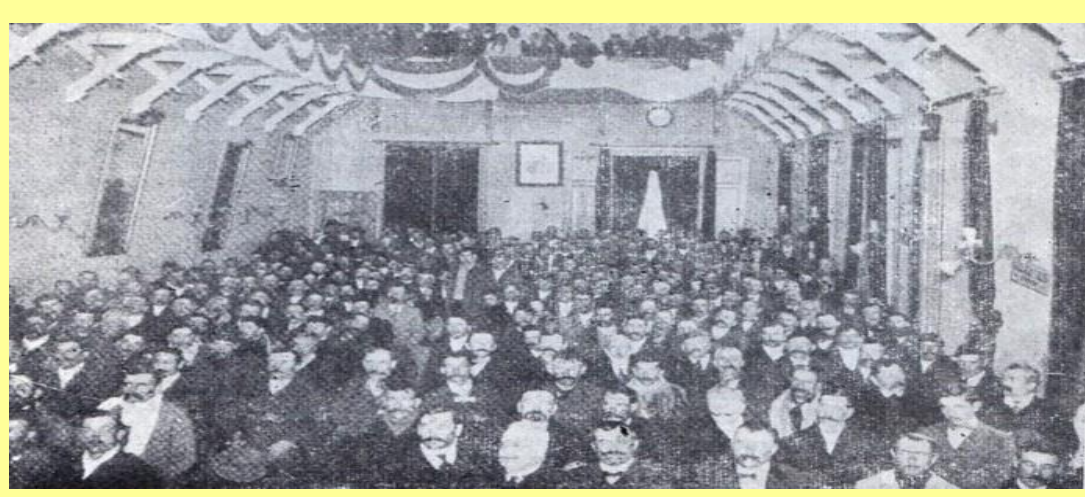
y tuvo su más claro exponente en la huelga ferroviaria de 1912. En abril de ese año la Intervención de la provincia de Santa Fe debió convocar al electorado para elegir por primera vez gobernador y legisladores según los términos de la Ley Sáenz Peña, y ello permitió que el radicalismo se imponga a sus dos adversarios: los "Acuerdistas" de neta raigambre conservadora y la Liga del Sur, a cuyo frente actuaba su fundador, Lisandro de la Torre. Por escaso margen de votos, la Unión Cívica Radical logra la victoria con el binomio Menchaca-Caballeroy pocos dias después tienen que hacerse cargo del problema que impulsó la lucha de los colonos.

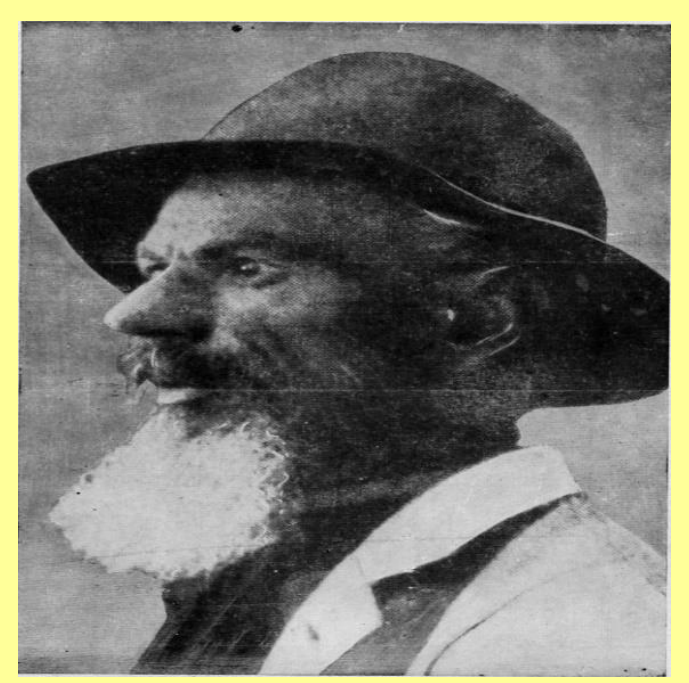

Antonio Noguera-Primer presidente de FAA

"El malestar económico reinante entre los agricultores del sur de Santa Fe, de la zona maicera por excelencia, debido a diversas causas concurrentes, como fueron la mala cosecha de 1911, encarecimiento de la mano de obra, falta de crédito, altos fletes, los trusts, etc., se venía acentuando e hizo crisis con la baja repentina experimentada por el maíz. Desde este momento los trabajadores del campo se pusieron de pie 
como un solo hombre y ya no pensaron más que en sacudir el yugo de la miseria recurriendo a la protesta colectiva" (Del informe del ingeniero Silvio A. Spangemberg, que en su carácter de director de la Escuela de Agricultura de Casilda, envió al Museo Social Argentino, y que está en los archivos de dicha institución; conf., Placido Grela "El Grito de Alcorta. Historia de la rebelión campesina de 1912", Editorial Tierra Nuestra, Rosario, 1958, pág., 11).

Era lógico que la crisis afectara igualmente al comercio del sur santafecino, el cual hizo causa común con los agricultores. Los chacareros habian contraído serios compromisos con los comerciantes que les habian abierto crédito, y a pesar que la cosecha de 1912 fue extraordinaria y superior a la de 1911, no les alcanzó para cubrir ni medianamente sus deudas. El agricultor Francisco Bulzani fue el principal gestor del movimiento agrario de Alcorta. Lo secundaron Luis Ricovelli, Hermenegildo Gasparini, Francisco Capdevila, Nazareno Lucantoni, L. Bó, Domingo Giampaulo, Damián Arfinetti, José Digliari, G. Klink, J. Castelarín y otros que han desfilado por las páginas de nuestra historia agraria.

Francisco Bulzani había llegado a Alcorta a comienzos del siglo XX y levantó su chacra en la colonia "La Sepultura", enorme latifundio que se extendía entre el pueblo de Alcorta y Bigand. Alli se encontraba la mayor parte de los agricultores de la zona que participaron activamente en la huelga agraria. Por eso se explica el lazo de unión que existía entre los chacareros de ambos pueblos vecinos, distantes 26 kilómetros entre sí. La chacra de Francisco Bulzani fue el primer escenario de la lucha agraria en 1912.

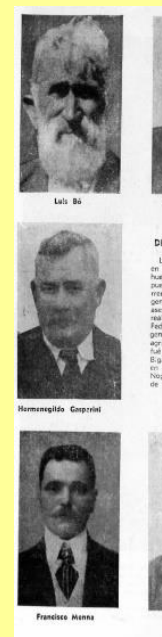

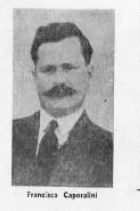
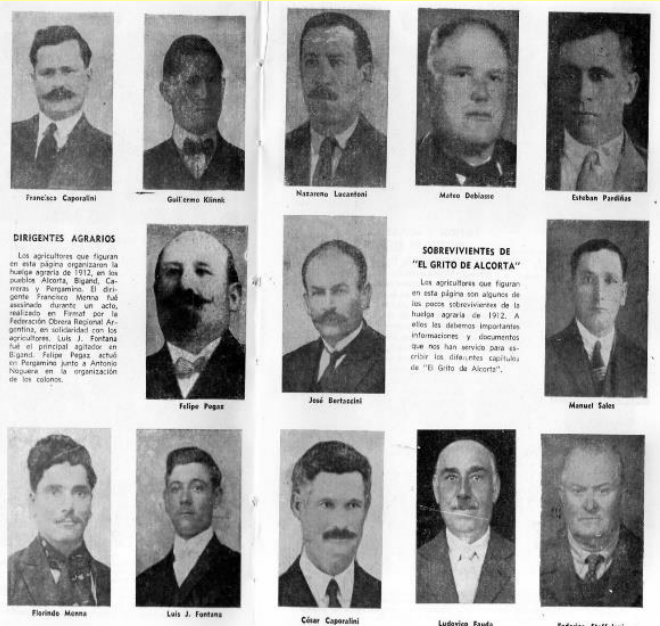

El comerciante Ángel Eugenio Bujarrabal fue el impulsor de la movilización en el pueblo. Su participación en la huelga agraria fue notable y estimuló la valiente lucha de los colonos. Con su mejor situación económica se colocó al lado de los campesinos y solventó su lucha. Fue así que a partir de los primeros días del mes de junio de 1912 se empezaron a realizar reuniones agrarias en el sótano del establecimiento comercial de don Ángel. La policía siguió la pista de los colonos más 
exaltados, y cuando éstos presumieron que podrían ser localizados en la casa de comercio donde se reunian, cambiaron el rumbo y celebraron sus reuniones gremiales en el hotel, propiedad de Juan Timone. A pesar de las persecuciones y la represión policial los colonos permanecieron fuertemente unidos. No cedieron el más mínimo terreno durante la lucha. Por las noches visitaban chacra por chacra y distribuian manifiestos por intermedio de los cuales aleccionaban a los colonos sobre el móvil de la huelga.

Bujarrabal no se circunscribió solamente a aconsejar a los agricultores o darles apoyo económico, sino que fue aún más allá todavía. Inició un movimiento solidario entre los comerciantes de distintos pueblos de la provincia, y se trasladó hasta Bigand, para entrevistarse con don Tomás Boretti, uno de los comerciantes más fuertes de la localidad. Organizó una reunión de comerciantes, quienes tomaron la resolución de prestar toda la ayuda necesaria a los huelguistas que actuaban en Alcorta, Bigand, Bombal, Carreras, Melincué y Máximo Paz.

En los primeros días del mes de junio de 1912 entra en escena el cura párroco de Alcorta. Pascual Netri, que así se llamaba el sacerdote sensible a los problemas campesinos que confrontó con los terratenientes, y se colocó junto a los sudorosos hombres del campo. Una noche fría del mes de junio de 1912, el sacerdote asistió a la reunión que se celebraba en el sótano del establecimiento comercial de Ángel E. Bujarrabal. Había sido invitado por los agricultores que periódicamente lo visitaban en la iglesia de Alcorta. Su presencia provocó reacciones y se discutió. Pero finalmente hubo acuerdo. Abandonando el sectarismo que dominaba a algunos, pactaron la unidad más férrea con el sincero sacerdote que en el camino de la lucha, demostraba su fe y su confianza en el triunfo de las causas populares.

La intervención del cura párroco en los sucesos de Alcorta tuvo consecuencias provechosas. Tiempo después visitó a su hermano José Netri, cura párroco de Máximo Paz, y lo convenció de que era una necesidad moral, espiritual y material apoyar la santa causa de la lucha campesina. El sacerdote José Netri resolvió también participar en las filas de los colonos de Máximo Paz, los cuales luchaban por una causa de redención social y humana. La valiente decisión de los dos sacerdotes sobrepasó los límites de Alcorta y Máximo Paz. En la iglesia de Alcorta se celebró una reunión de eclesiásticos, es decir, de curas párrocos de San José de la 
Esquina, Arteaga, Alvear, de Máximo Paz y de Alcorta. Resolvieron apoyar con todas sus fuerzas la huelga agraria contra la explotación que sufrian por los grandes propietarios de tierras. El cura Pascual Netri llegó a convertir el atrio de la iglesia en centro de las reuniones campesinas. No pocos manifiestos se redactaron en la iglesia, los que impresos en Rosario, fueron distribuidos en las colonias y en los pueblos santafesinos.

Ya no se hablaba ni se discutía de diferencias ideológicas. Socialistas, anarquistas y católicos lograron confraternizar, destrozando los sectarismos dogmáticos. Tenían claro contra quienes confrontaban. Dirigentes y campesinos marchaban del brazo unidos por una misma causa. Posteriormente, también se adhirió el cura párroco de San Genaro, permitiendo que las concentraciones agrarias se realizaran a la puerta de la iglesia. Sus nombres, en cierto modo, están ligados a los de Juan Ignacio Gorriti, Justo Santa María de Oro, Fray Luis Beltrán, Benjamín José Lavaysse, Fray Mamerto Esquiú, y más cerca en el tiempo al del padre Mujica, a Monseñor Angelelli y al del Monseñor Jaime de Nevares.

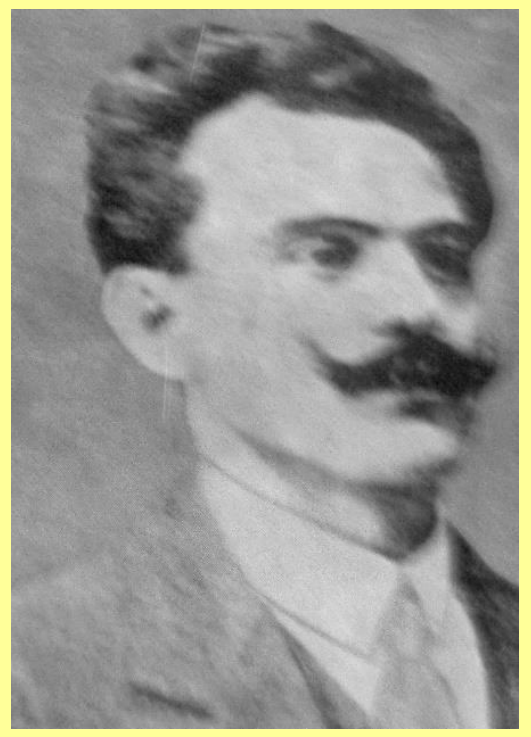

Dr. Francisco Netri

Pascual Netri se encargó también de poner en contacto a los colonos con su hermano, el abogado Francisco Netri. Viajó a Rosario con una comisión de chacareros y se entrevistó con él, exponiéndole el problema. El letrado de origen napolitano los escuchó atentamente. Después dialogó con ellos. Finalmente aceptó el ofrecimiento de ser el asesor de los huelguistas. Sabía Netri que era dificil la tarea que se había impue sto y muy serio el compromiso que terminaba de contraer con los chacareros, pero estaba seguro que luchaba por un motivo que sus hermanos clérigos calificaron de "causa santa". Como consecuencia de su heroica lucha, el 5 de octubre de 1916, el doctor Netri fue asesinado cobardemente en una calle de Rosario por un sicario de la oligarquía terrateniente. Qué otro autor intelectual pudo tener esa muerte injusta. Netri pasará a la historia como gestor, conductor y organizador de la primera huelga agraria en nue stro país. Más argentino que muchos terratenientes y abogados de empresas imperialistas, pagó con su vida la hidalguía de un gesto histórico. 
La hoja del calendario marcaba el domingo 25 de junio de 1912. El día era lluvioso y frío. La noche anterior sopló viento del Este. Los caminos se pusieron intransitables. Antes del medio día empezó a silbar el viento pampero. Las nubes se despejaron y un cielo azul se abrió ante la vista de los agricultores. Si numerosa había sido la primera asamblea realizada por los colonos el 17 de junio, más lo sería ésta, a la que asistirian agricultores de Alcorta, Bigand, Bombal, Carreras, Firmat y San Urbano. Cientos de agricultores se concentraron ese día frente al local de la Sociedad Italiana. A la convocatoria respondian dispuestos a los mayores sacrificios. El comercio de Alcorta cerró sus puertas. La colonia y el pueblo se congregaron en masa para escuchar la palabra de los agrarios. No había ya ninguna duda de que la tempestad campesina se avecinaba. La huelga era un clamor popular que nada ni nadie podría detener (Conf., Placido Grela "El Grito de Alcorta. Historia de la rebelión campesina de 1912”, Editorial Tierra Nuestra, Rosario, 1958, pág., 69). La huelga logró conmover a todos los círculos sociales, agrarios y politicos del país.

A las tres de la tarde de ese día comenzó sus deliberaciones la histórica asamblea, de la cual habría de surgir el grito de rebelión campesina. La asamblea se realizó con la presencia de más de dos mil colonos. Hubo indescriptible entusiasmo. El espectáculo fue memorable. También asistió el cura párroco Pascual Netri y el comerciante Ángel E. Bujarrabal. El primero en hacer uso de la palabra fue el dirigente Francisco Bulzani. Entre otras importantes cosas, dijo:

"No hemos podido pagar nuestras deudas y el comercio, salvo algunas honrosas excepciones, nos niega la libreta. Seguimos ilusionados con una buena cosecha, y ella ha llegado, pero continuamos en la miseria. Apenas si nos alcanza el dinero para pagarle al almacenero que nos viene surtiendo todo el año. Esto no puede continuar así. Tenemos que ponerle punto final a tan triste como temeraria situación, caso contra rio se producirá el éxodo campesino que debemos evitar a cualquier precio. Los propietarios se muestran reacios a considerar nuestras reclamaciones y demandas. Los hemos invitado a la reunión que hemos realizado el 17 de este mes en este mismo lugary, después de prometer que asistirian, no se les vio ni el polvo. Creen que lo que nosotros pedimos no se ajusta a la realidad. Pero si hoy sonrien por nuestra protesta, 
pueda que mañana se pongan serios cuando comprendan que la huelga es una realidad..." (Conf., Placido Grela "El Grito de Alcorta. Historia de la rebelión campesina de 1912”, Editorial Tierra Nuestra, Rosario, 1958, pág., 69/70).

Impulsado por el entusiasmo de la Asamblea, Bulzani propuso la declaración de huelga en toda la colonia de Alcorta y su palabra recibió el asentimiento general. A partir de ese instante "El Grito de Alcorta" recorrió todos los pueblos y colonias de la República. Miles de colonos la proclamaron de viva voz. El país se enteró de la valiente decisión de los sufridos trabajadores de la tierra levantados en contra de los terratenientes y de los que en nombre de una colonización caprichosa, explotaban a cientos de inmigrantes que habian llegado al país.

Los agricultores de Alcorta escribieron en 1912 la página más brillante de la historia del movimiento agrario argentino, adelantándose a los de Bigand que recién lo hicieron el 30 de junio del mismo año. La Sociedad Italiana, la Iglesia, y la casa del comerciante Ángel Bujarrabal fueron lugares frecuentados por los agricultores durante y después del histórico pronunciamiento. El 2 de julio de 1912 se realizó en Alcorta una manifestación imponente.

La huelga continuó extendiéndose, y el eco de la rebelión llegó hasta la Cámara de Diputados de la Nación. Juan B. Justo, el 10 de julio con motivo de la fundación del Partido Socialista de Villa María, pronunció una conferencia en dicha localidad sobre problemas agrarios. De regreso de su gira por Córdoba, el 11 de julio, a solicitud del doctor Francisco Netri pronunció su anunciada conferencia. Y después el 29 de julio de 1912 desde su banca de diputado interpeló al Ministro de Agricultura, doctor Adolfo Mujica, sobre el conflicto agrario. Juan B. Justo censuró con fuerza la política que en materia agraria y frente a la huelga, seguian las autoridades nacionales. Enfrentó a la oligarquía criolla y desnudó moralmente al ministro de Agricultura. El nombre de Juan B. Justo se encuentra ligado a las luchas obreras y campesinas contra la oligarquía nacional. En la Cámara de Diputados de la Nación se suscitó un acalorado debate, durante el cual acusó al gobierno de favorecer a la oligarquía nacional y de perjudicar al pueblo consumidor y a los agricultores, gravando con impuestos los elementos y maquinarias destinados a la agricultura. 


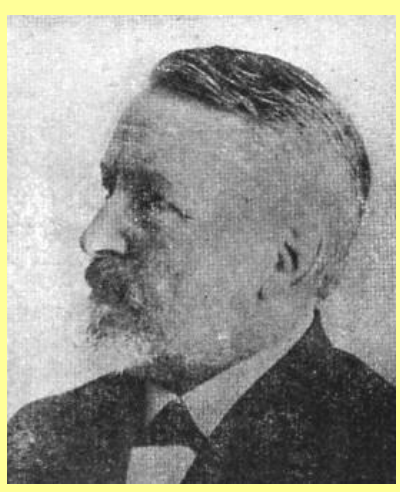

Dr. Juan B. Justo

Mientras en los pueblos de la provincia se repetían las concentraciones agrarias. Era su lucha contra el "régimen", palabra con la que Yrigoyen designó a los gobiernos nacionales y provinciales, que se instalaron desde 1880. El régimen era la usurpación de la soberanía por un grupo de hombres, por una oligarquía. Era una "conjuración oficial" que todo lo arrasa (conf., Manuel Gálvez, "Vida de Hipólito Irigoyen. El hombre del misterio", $2^{a}$ edición, Buenos Aires, 1939, pág. 164). La oligarquía terrateniente le exigió al gobierno radical de Santa Fe la adopción de rápidas medidas de seguridad para evitar la pérdida de la cosecha. El gobierno accedió inicialmente y las fuerzas policiales de campaña cometieron los primeros desmanes. Hubo choques entre huelguistas y policias, y muchos dirigentes fueron privados de su libertad. El gobierno santafesino acosado por la reacción conservadora permitió que se cometieran atropellos lamentables en contra de los campesinos. Pero cuando comprendió la realidad del problema, adoptó otra postura menos parcial. El gobierno de la provincia de Santa Fe intervino y propició una solución que pusiera término al conflicto. Al constatar que el chacarero vivia sin ninguna clase de protección y expuesto siempre a la insaciable voracidad de los propietarios de las tierras tomó la decisión de defenderlos.

En el mes de julio designó una comisión in tegrada por tres miembros a los efectos de que se entrevistase con los propietarios y los agricultores, para poder contar con elementos de juicio recogidos en el mismo teatro de los sucesos. La Comisión la integraban los doctores Ricardo Caballero, Daniel J. Infante y Toribio Sánchez, los cuales se entrevistaron con los propietarios en la Sociedad Rural; con los representantes de la Bolsa de Comercio y con los agricultores. De cada una de aquellas reuniones sacaron experiencias y elementos de juicio.

Existieron contradicciones y pugnas entre los dueños de las tierras. Los miembros de la Cámara Sindical de la Bolsa de Comercio de Rosario, cuando fueron entrevistados por los integrantes de la Comisión oficial que presidía el doctor Ricardo Caballero, se declararon abiertamente partidarios de la rebaja del arrendamiento. Esa posición los colocaba en contra de los propietarios aglutinados en la Sociedad Rural de Rosario. El 17 de julio del año 1912 se celebró una reunión en la sede de 
la Cámara Sindical de la Bolsa de Comercio, a la que asistieron los representantes del gobierno de la provincia de Santa Fe. Allí reconocieron públicamente la justicia de los reclamos de los agricultores. Produjeron un extenso informe, en el cual puntualizaban las causas de la huelga agraria que amenazaba con extenderse a las provincias de Buenos Aires, Córdoba y Entre Ríos. Quién quiera conocer profundamente aquel movimiento de campesinos, deberá leer detenidamente ese documento, pues allí se observan muchas cosas que algunas veces se ocultan. En ese documento hay clarificadores conceptos como el que sigue:

"Creemos haber llegado al término de nuestra tarea y pasamos a consignar las opiniones que hemos formado. Entendemos y estamos seguros de que todo hombre de buen criterio que estudie desapasionadamente este asunto ha de entender lo mismo; que es preciso ponerse en el actual conflicto de parte de los colonos porque está de su lado la razón. No pueden más, se les exprime como a limones; no dan, no pueden más. Los arrendamientos han ido elevándoseles de contrato a contrato o de año en año (porque hay propietarios que no han querido hacer contrato para tener la posibilidad de imponer elevaciones graduales), en términos que para muchos resultan absolutamente insoportables. Hay quien cobra el cincuenta y cuatro por ciento de la cosecha; hay quien cobra treinta y cinco pesos en dinero y el veinte por ciento de la cosecha, además. Y esto ha sido hecho cuando los propietarios ganaban al mismo tiempo enormidades sin ningún trabajo, porque las tierras se valorizaban, en forma que se puede citar casos en los cuales se cobra de alquilerpor cuadra y año, más de lo que el dueño actual le ha costado comprarla".

En el capítulo titulado "Alquileres y gabelas", los miembros de la Comisión destacaron las leoninas imposiciones de los propietarios de tierras:

"En muchísimos casos se imponian gabelas tan insoportables o más que los alquileres. Según muchos casos y contratos, el colono no tiene pastoreo; de manera que ha de pagarcon tal objeto el promedio de la cosecha en la que labre o en lo vecino si lo suyo ha dado poco. Tiene que trillar con las máquinas del patrón o con la que el patrón le señale. Tiene que vender su cosecha al patrón o a quien el patrón le indique; no puede vender la cosecha sino después de haber pagado la renta; tiene que pagar él la trilla y la bolsa de la parte que al patrón le corresponde; ha de poner esa renta en la estación o en el galpón que le señale dentro de cierto radio; hay quien obliga a pagarle el tercio de las gallinas o cerdos que el colono crie, y hasta el de los huevos que recoge; hay quien exige el depósito de cinco pesos por cuadrasen garantia de que 
el campo está bien limpio y bien cultivado, y lo retiene en su poder años y años sin pagar interés alguno para ello. Se impone a los colonos la renuncia a los beneficios que las leyes tienen reconocidos por razones de humanidady orden público" (Conf., Placido Grela "El Grito de Alcorta. Historia de la rebelión campesina de 1912", Editorial Tierra Nuestra, Rosario, 1958, pág., 125).

Aunque en el informe había más todavia, estos párrafos denuncian las

\section{arbitrariedades que cometian los terratenientes contra la masa campesina.}

Verdades de a puño pregonaron los funcionarios radicales. La Comisión señalaba que la solución estaba:

"En definitiva para todas las cuestiones de

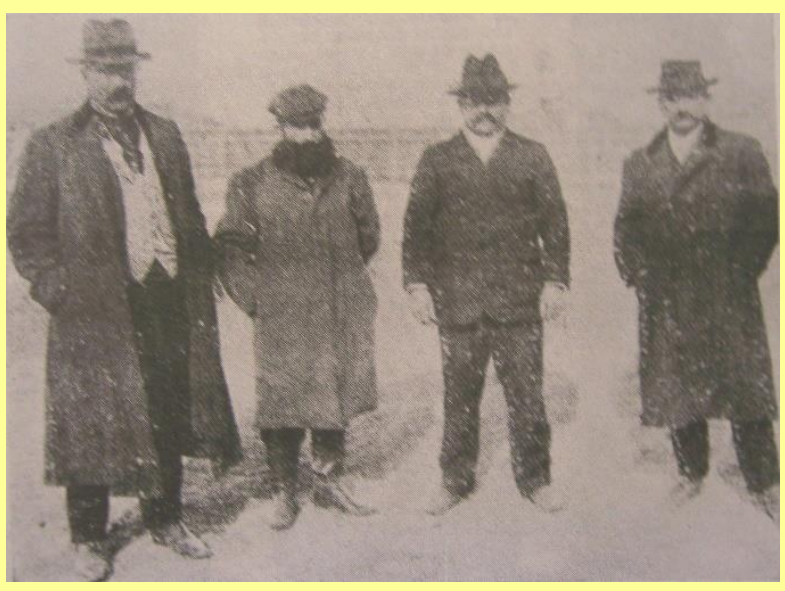

"Dirigentes Agrarios de Alcorta"-Junio de 1912 esta indole, en la reforma de toda la legislación común o constitucional que se oponga al establecimiento de la siguiente facultad que consideramos de derecho pleno de todo labrador en todas las partes del mundo. El jefe de familia, labrador, que no tenga tierra propia y la desee para labrarla por sí y por los suyos, tiene derecho a que se expropie para él, en el paraje que él designe, siempre que se trate del perimetro de una propiedad mayor de mil hectáreas y no cultivada por el dueño; una fracción no mayor de veinticinco hectáreas por el precio asignado para la contribución directa y un cincuenta por ciento más, la mitad del cual se refuta tolerancia en la valuación para el impuesto, y la otra mitad precio de afeccióny compensación de trabajo a empleary el tiempo a perder en el nuevo empleo de los capitales que ha de hacer el propietario expropiado". (Conf., Placido Grela "El Grito de Alcorta. Historia de la rebelión campesina de 1912”, Editorial Tierra Nuestra, Rosario, 1958, pág., 135).

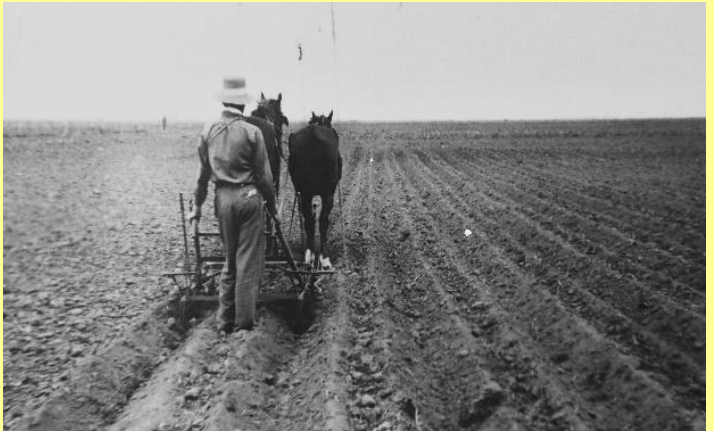

Era sostener el principio de "la tierra para el que la trabaja". La posición progresista del radicalismo que había accedido al gobierno provincial queda plenamente establecida. Los agricultores de Santa Fe comprendieron que el gobierno los interpretaba haciéndose eco de sus reivindicaciones. 
Sin embargo, no todo estaba hecho ni el conflicto habria de solucionarse con un informe. No se logró subdividir la tierra y entregarla a los campesinos. La tierra no fue para quien la trabaja. Lo que el gobierno santafecino tampoco pudo evitar fue la violenta arremetida de las fuerzas policiales contra los agricultores ni los encarcelamientos injustos. Funcionarios policiales y jueces de paz de los pueblos de campaña acataban las indicaciones de los terratenientes y desoían a las del gobierno. También mucho se tuvo que discutir antes de llegar a un acuerdo entre agricultores y representantes del gobierno. Finalmente, se resolvió dar por aprobado un convenio sobre cuyas bases descansaria en lo futuro todo arreglo para levantar la huelga agraria. En realidad, las cláusulas del convenio suscripto no encerraban mejoras sustanciales para los agricultores; pero con él algún trecho se había avanzado en la dura lucha que sostenian.

A fines de agosto de 1912 la mayor parte de los campesinos de Alcorta, habian normalizado sus tareas. En asamblea general acordaron levantar el movimiento sólo en los lugares donde los propietarios o subarrendadores habian aceptado las condiciones impuestas por los chacareros. También se resolvió prestarles el mayor apoyo moral y material a los colonos de otros pueblos que continuaban en conflicto.

La huelga agraria de 1912 fue apoyada por casi todos los sectores políticos progresistas del país. Sólo el círculo reaccionario de los propietarios de tierras se negó a reconocer la justicia reclamada por los campesinos. En cuanto a la prensa se refiere, el diario "La Capital" de Rosario también la apoyó decididamente. El diario había sostenido una línea favorable a la candidatura del Dr. Lisandro de la Torre, fustigando a radicales y "acuerdistas". No obstante aquella definición en el orden político, sus páginas en más de una oportunidad ensalzaron los aspectos progresistas del gobierno radical frente al conflicto de los agricultores, pero censurando también sus desaciertos.

De tal modo la masiva agitación agraria duró más de tres meses consecutivos y afectó a casi todas las colonias de las provincias de Buenos Aires, Santa Fe y Córdoba. Fue el primer grito de protesta campesina dado por los rudos hombres de la tierra. Iniciaban una marcha dificil y penosa. Pero lo cierto es que alli empezaron las primeras conquistas agrarias; se logró la rebaja del precio de los arrendamientos, surgió la Federación Agraria Argentina, y en la Cámara de Diputados se presentaba el primer proyecto de ley que trató el contrato agrario. 
La lucha campesina habia dejado su semilla y con seguridad fue causa directa de la Constitución que se sancionó en Santa $\mathrm{Fe}$ en el año 1921. La nueva situación política que tenía el país a partir de la sanción de la Ley Sáenz Peña, permitió una directa presencia de partidos politicos afines a los sectores populares, tanto a nivel nacional con el Presidente Yrigoyen, y la Democracia Progresista de Lisandro de la

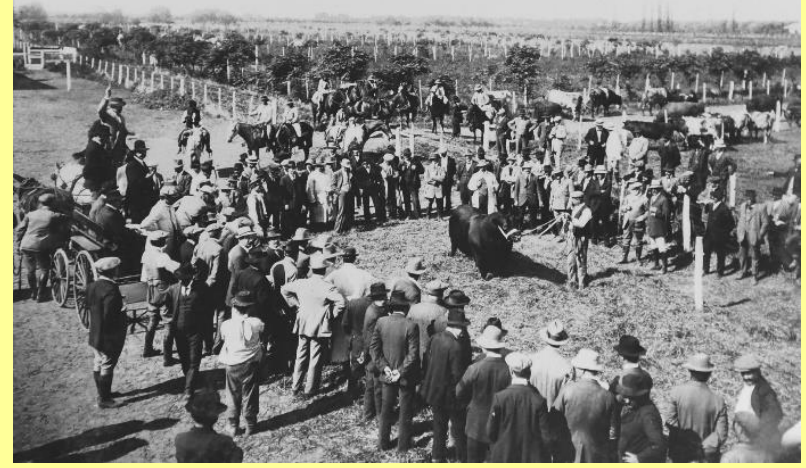
Torre en la provincia de Santa Fe.

Tampoco es un hecho menor que la Convención Constituyente que el 13 de agosto de 1921 sancionó la nueva Constitución de la Provincia de Santa Fe, fuera presidida por Manuel J. Menchaca, quien fue gobernador de la provincia precisamente durante los días de "El Grito de Alcorta". La Constitución, había institucionalizado un texto avanzado para esa época. En el Capítulo II, donde desarrolla las "Bases del Régimen Económico y del Trabajo", se encuentran las voces de los chacareros que lanzaron "El Grito de Alcorta":

Art. 28.- "El Estado, por medio de una legislación adecuada, propenderá a mejorar las condiciones de vida y de subsistencia social, fomentando y protegiendo la producción, la cooperación, la mutualidad y el ahorro; proveyendo a la comodidad, salud, seguridad y bienestar general de los obreros; fijando la jornada máxima de trabajo y el salario minimo; asegurando la higiene de los talleres y de las fábricas; destinando una parte de la renta fiscal para la construcción de casas para obreros; reglamentando el trabajo de las mujeres y menores y estableciendo cámaras de arbitraje, de las que formarán parte representantes de asociaciones patronales $y$ gremiales legalmente autorizadas para resolver los conflictos suscitados entre patrones y obreros".

Art. 31.- "La Provincia adquirirá tierras aptas para venderlas en lotes no mayores de cincuenta hectáreas, en no menos de veinte anualidades y a precio de costo a agricultores argentinos, nativos o naturalizados, utilizando como recursos los provenientes en todo o en parte, de los impuestos al mayor valor de la tierra libre de 
mejoras; de un adicional a la contribución directa que abonarán los latifundios y los demás que creara con este fin la Legislatura. También se establecerá con el mismo objeto un impuesto adicional a la Contribución Directa que abonarán los propieta rios que vivan fuera de la República".

\section{Pero}

esa Constitución fue atacada por cuestiones formales. $\mathrm{Se}$ argumentó que fue sancionada una vez vencido el término que tenía fijado para sesionar la convención y por ende, fenecido el mandato que se le habia otorgado a los constituyentes. Se invocó la "restricción

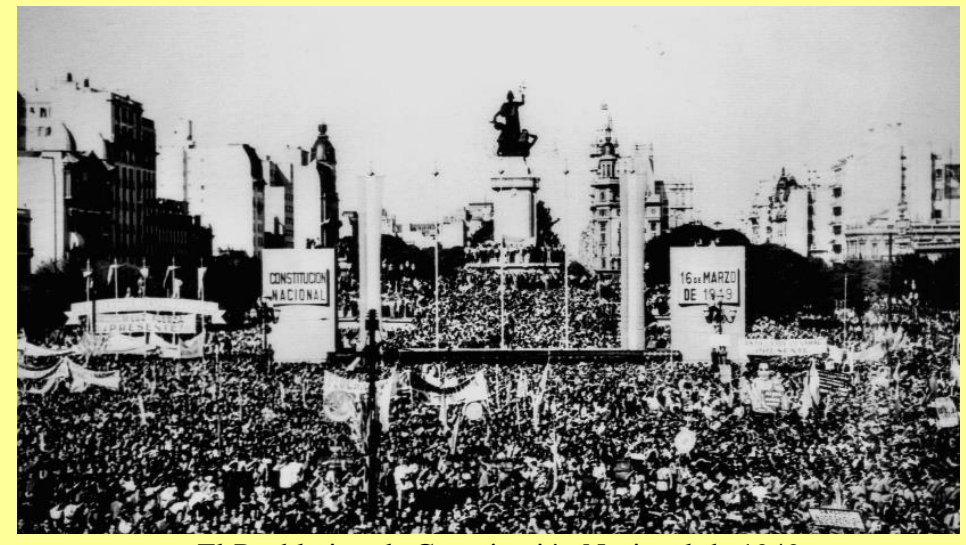

El Pueblo jura la Constitución Nacional de 1949 constitucional del mandato" (Véase M. A. Montes de Oca, "La Convención de Santa Fe de 1920-1921, prórroga de su mandato", Establecimiento Gráfico de J. L. Ribero \& Cía,, Buenos Aires, 1922). Ciertamente, en la Argentina todavía no predominaban los sectores populares en el ámbito de la Constitución real y ese texto de la Constitución escrita de 1921, confrontaba con los poderosos sectores de la oligarquía nativa y de los representantes del capital extranjero. En definitiva, sufrió los avatares del predominio de la Constitución real sobre la Constitución jurídica.

Ante situaciones como las mencionadas había señalado Sampay que en el caso de que "aplicando la idea de justicia oligárquica que la Constitución real tuviese instituida como fin, se quisiera invalidar la sanción de una reforma constitucional dirigida a mejorar las condiciones de vida del pueblo, ello, en puridad, sería un acto de subversión contra el progreso de la justicia" (Arturo E. Sampay, "Constitución y Pueblo", 2a edición, Cuenca Ediciones, Buenos Aires, 1974, pág., 86).

Sin duda, ello es lo que aconteció en realidad, con la Constitución de Santa Fe de

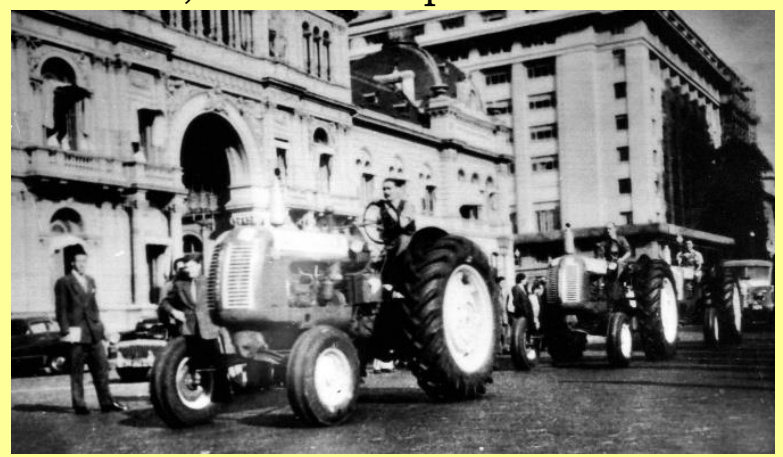
1921.

Algo similar ocurrió años después con la Constitución Nacional de 1949, que en su Capítulo IV, sobre la función social de la propiedad, el capital y la actividad económica, había establecido que "la propiedad privada tiene una función social y, 
en consecuencia estará sometida a las obligaciones que establezca la ley con fines de bien común. Incumbe al Estado fiscalizar la distribución y la utilización del campo e intervenir con el objeto de desarrollar e incrementar su rendimiento en interés de la comunidad, y procurar a cada labriego o familia labriega la posibilidad de convertirse en propietario de la tierra que cultiva" (artículo 38).

Es así, que a través de la intervención del Estado en el proceso económico, se captó la renta agraria con la que entre 1945 y 1955 se avanzó en la industrialización de la Nación. Por eso para los más reaccionarios sectores conservadores, lo central fue y es evitar que se reconstruya un Estado con la suficiente capacidad de intervención, que impida a los grandes conglomerados agrícola-ganaderos diseñar a su antojo y en su beneficio exclusivo, cual será el sistema de producción agraria en la tierra de los argentinos. Sabido es que la Constitución de 1949 fue dejada sin efecto por un golpe de Estado, con el que se fue haciendo patente la supraconstitucionalidad de facto, que luego se utilizó abiertamente por los últimos gobiernos de ese signo en 1966 y 1976. Quienes los apoyaron desde la política, la judicatura, los claustros universitarios, y en distintas organizaciones empresarias, se olvidaron de las "formalidades" y la Constitución escrita perdió su calidad de Ley Suprema.

¿El "Grito de Alcorta" se encuentra hoy presente en los cortes de rutas? Pero qué tiene que ver ese heroico movimiento de los explotados colonos arrendatarios, con un "lockout" patronal que tiene su origen en el deseo de retornar y mantener un esquema agro-exportador, con predominio del poder político en manos conservadoras, como en ese entonces. Sólo el desconocimiento absoluto de lo que fue ese movimiento de 1912, o la intención aviesa de utilizarlo en beneficio de un esquema de negocios dominado por los grandes poseedores de tierras, multinacionales cerealeras, contratistas y exportadoras, puede justificar una respuesta afirmativa. Los objetivos de aquella lucha no se encuentran representados por quienes ahora están a la vera de los caminos en defensa de ganancias extraordinarias y promoviendo antiguas politicas "neoliberales" que vedan la intervención del Estado en el proceso económico.

Lo primordial para los sectores que todavia predominan en la Constitución real del país es precisamente evitar que se reconstituya en la Argentina un Estado con 
capacidad de intervención, que pueda limitar la potestad de los mercados para conformar a su antojo vida y milagros de los sectores populares. Si no existe el Estado que referimos, no se podrán aplicar retenciones ni otras medidas de política económica diferentes a las concepciones "neoliberales" que primaron en las últimas décadas del siglo pasado. Tal es el centro de lo que se juega. Las épocas de mejoría para el pueblo fueron cuando -desde la democracia sustantiva y no formal- se abrieron etapas de ascenso popular, que limitaron el señorío del poder de los sectores

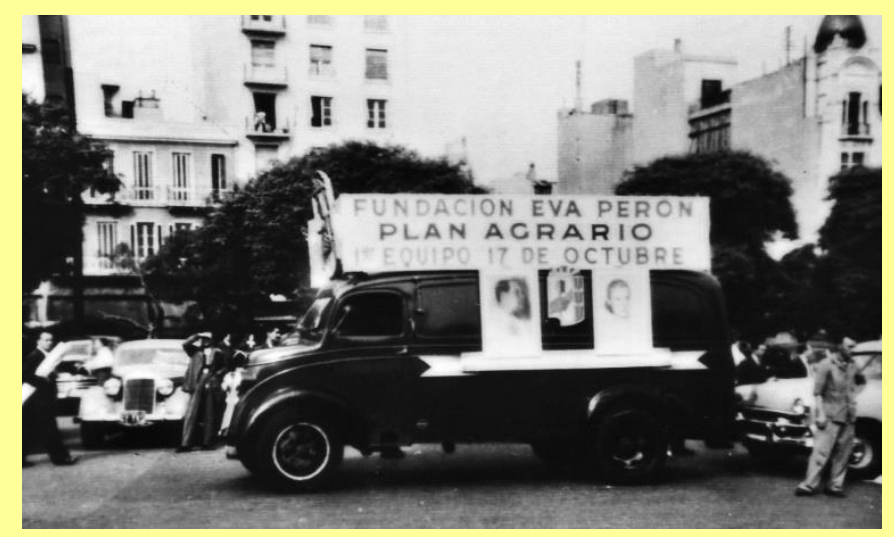
dominantes. El Yrigoyenismo (19161922 y 1928-1930), el primer peronismo (1946-1955) o la fallida experiencia del retorno de Perón (1973-1974) fueron ejemplos históricos de avances populares, que lograron domesticar y moderar relativamente, desde la politica, al poder económico.

Los ciclos golpistas de 1930, 1955, 1966 y 1976, más la hiperinflación que tumbó a Raúl Alfonsín o la larga noche neoliberal menemista significaron etapas en las que la derecha logró torcer en su beneficio la trabazón entre el poder político y el poder económico (conf., Raúl Isman, "Piquetes y cacerola. La lucha es una sola - Segundas partes nunca fueron buenas”, Revista Electrónica Redacción Popular. raulisman@yahoo.com.ar www.geocities.com/raulisman).

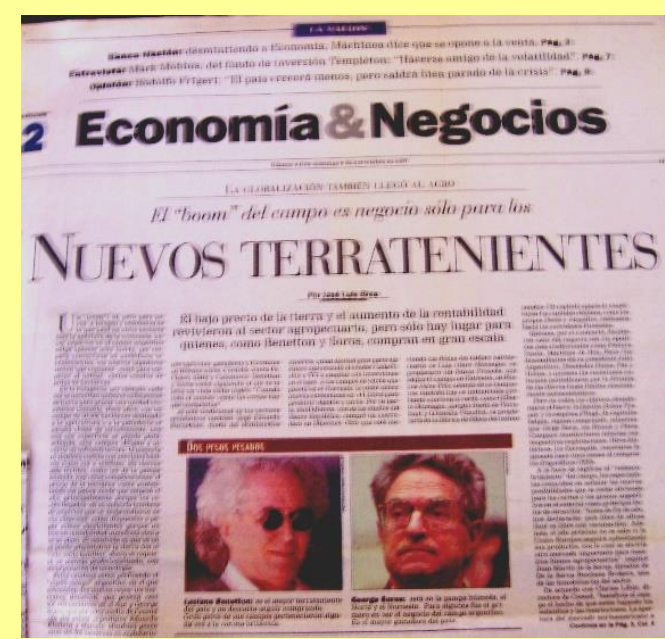

Según “La Nación”, el boom del campo es negocio sólo para los "Nuevos Terratenientes"
El aumento gradual de las retenciones y en particular las correspondientes a la soja es el motivo que ahora ha empujado "a la sempiterna, antisolidaria oligarquía terrateniente nacida en nuestro país". La acompaña una vez más "la desorientada Federación Agraria Argentina, que hace años no se atreve a separase de los oligarcas y hacer un planteo digno de reclamo de tierras, de límites a la extensión de los latifundios, de cese y recuperación de las enormes cantidades de tierras extranjerizadas 
y de cambio general de la política agropecuaria”. La FAA. cumple el deplorable y triste rol de servir de escudo a los terratenientes más reaccionarios. El tránsito de la Argentina industrial, tecnológica y científica existente entre 1945 a 1989, a la Argentina factoría agroexportadora actual, contó con la mirada complaciente de la FAA.

Esta política permitió la devastación de los pequeños y medianos productores y el tránsito de una producción centrada en el desarrollo de alimentos en gran cantidad

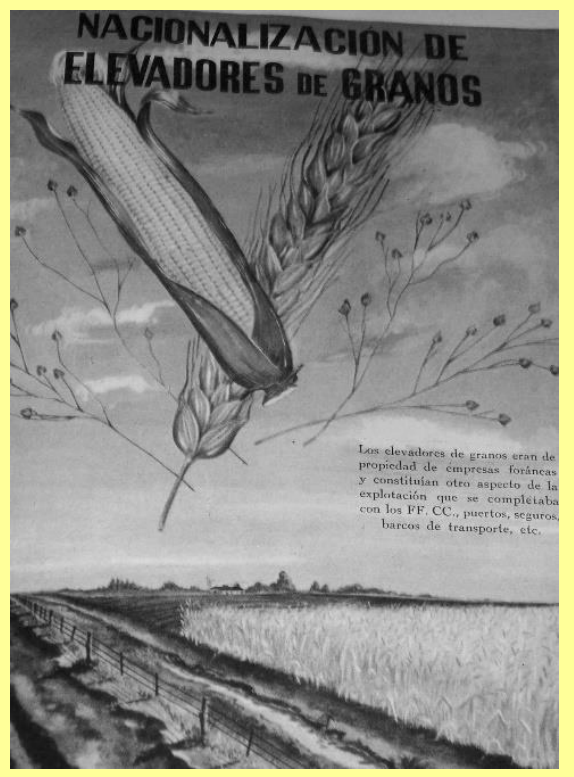
y de gran calidad, hacia un 'campo' que produce forraje barato -'pasto soja'- para vender a China, India y la UE subsidiando de tal forma la industrialización de estos países a costa de nuestra industrialización, nuestra producción lechera, ganadera, porcina, frutal, hortícola, ovina y regional. Se repite el modelo de siempre en el campo, donde la SRA -la vieja oligarquia terrateniente- se opone a cualquier control por parte del Estado de su tasa de ganancia lograda a costa del esfuerzo de toda la nación y en particular, mediante el monopolio absoluto de la renta agraria por su dominio total sobre las tierras existentes en la nación.

Oligarquía terrateniente implica que 6900 propietarios (familias, empresas o empresas-familias) sean dueñas del $49.7 \%$ de la superficie cultivable y productiva del país, o que según el Censo Agropecuario de 2002, 936 terratenientes poseen 35.515.000 Has (casi toda la superficie en cultivo), un promedio de 38.000 has c/u. Por el contrario 137.021 agricultores poseen sólo 2.288 .000 has, con un promedio de 16.7 has c/u.

En 1966 poseíamos más de 600.000 productores agropecuarios, hoy sólo restan 330.000, de tal forma la oligarquía terrateniente recuperó con creces las tierras que Perón había obligado a venderles a los chacareros arrendatarios a través del $1^{\circ}$ y $2^{\circ}$ Plan Quinquenal. En vez de enfrentar a la SRA y CARBAP, y denunciar la concentración y brutal extranjerización de la tierra, unidas a la destrucción de un modelo soberano de producción de alimentos y su reemplazo por un modelo factoría productor de forrajes baratos para la exportación, la F.A.A. se une a los terratenientes y las multinacionales granarias que se adueñan hoy de la renta agraria en lucha 
contra las retenciones (conf., Alberto J. Lapolla, "Retenciones, piquete garca, la FAA en mala compañia; las mentiras de Huergo y modelo agropecuario", www.desruralypoliticas.com.ar - 15.03.2008).

Apenas tres gigantes mundiales concentran del 45 al $50 \%$ de los despachos al exterior de la cosecha Argentina: Cargill, Bunge y Dreyfus. Son quienes más exprimen a los pequeños productores. De las casi 95 millones de toneladas de granos que se cosecharán en 2008, más del 70 \% pertenecen a grandes y medianos productores agropecuarios de la pampa húmeda. En estos grupos aun con las retenciones móviles, la rentabilidad es tan grande que supera por lejos los niveles medios de la economia.

La pelea en estos días se manifiesta por la renta extraordinaria. En la actualidad estas altísimas utilidades tienen que ver, fundamentalmente, con los precios internacionales de los commodities de productos agrarios. En rigor, la suba de retenciones no afecta las cuentas del pequeño productor. No pasa de una situación de rentabilidad a otra de pérdida, sino que sus ingresos serán incluso mayores a los proyectados en el momento de sembrar. Cuando el productor sembró soja en octubre pasado tenía una perspectiva de ingresos de 231,4 dólares la tonelada y en este momento, pese al incremento de las retenciones, se llevará 282 dólares. De eso los "ruralistas" prefieren no hablar, "quieren quedarse con todo".

Las retenciones a las exportaciones agropecuarias, uno de los mecanismos dedicados a la redistribución de ingresos, nunca conformaron a los que desean quedarse con todas las ganancias procedentes de la extraordinaria cotización de las materias primas en mercados no tradicionales, sobre todo el de los mayores importadores asiáticos.

Ciertamente, las retenciones móviles son el primer paso contra la política de "sojización". Salir de ello significa antes que nada, redistribuir la tierra y repoblar el territorio nacional devastado por el "pequeño poroto" y recrear la Junta Nacional de Granos, en el marco de un Plan Agrario que beneficie al país. El nivel de ingresos del 
sector que ejerce el control sobre la propiedad de la tierra y por ende de la producción,

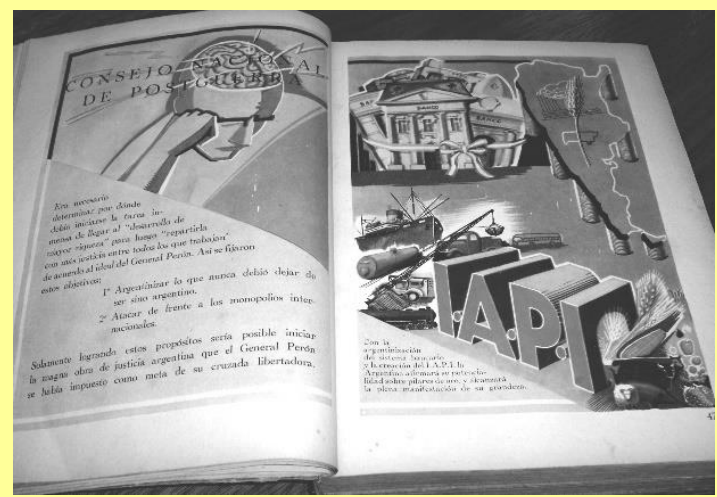
es escandaloso y como siempre suntuario. Ya en la campaña 2004-2005 los propietarios de la región pampeana, en el centro del proceso de la "sojización", recibieron en concepto de Renta Terrateniente o renta de la tierra por el arrendamiento de las mejores tierras del mundo, la suma de algo más de 3.000.000.000

de U\$S, más de 10.000 millones de pesos. Es decir una masa sideral de dinero sin invertir ni arriesgar un solo peso.

En la actualidad esas cifras son mucho mayores. Sí a eso se suma que la mayoría no paga impuestos o lo hace por actividad ganadera y no agrícola, con tasas irrisorias de impuesto inmobiliario, y que las multinacionales exportadoras pagan impuestos en función de declaración jurada, se comprenderá que el monocultivo sojero deja muy poca riqueza real, valor agregado productivo en la sociedad argentina. A su vez los trabajadores rurales son echados sin indemnización y contratados en negro cuando se los necesita (conf., Alberto J. Lapolla, ibidem).

Como vemos, poco ha cambiado en la relación de la nación con la vieja oligarquía terrateniente, ahora asociada a algunos pools empresarios. Ella sigue allí y tan poderosa como siempre. La oligarquía una vez más, usa su poder económico contra el pueblo y la nación, reclamando quedarse con la totalidad de los precios internacionales para sus productos en el mercado interno, lo que supone, y ellos lo saben, el hambre para el pueblo y el subdesarrollo de la Nación, como lo hizo siempre.

¿Cuál es la discusión de fondo actualmente en la Argentina? Como expresó la Presidenta Cristina Fernández de Kirchner, durante el encuentro de Parque Norte (27.03.08), esa discusión es "la distribución del ingreso y un modelo de pais". Es, ni más ni menos, que la renovación del debate sobre el rumbo del desarrollo nacional y social de los argentinos.

Las minorias que no ganaron las elecciones no tienen el derecho institucional de imponer por la fuerza la política económica. El paro transformó a la inmensa mayoría de la sociedad Argentina en acosado rehén, cautiva de un lockout básicamente 
orquestado por los "dueños de la tierra" y el conglomerado económico exportador altamente concentrado. Ante el salvajismo concreto de un paro nacional del agro en extremo autoritario, desabastecedor, amedrentador, inflacionario, a partir de una actitud soberbia de utilización de poderes y técnicas de prepotencia propias de oscuros tiempos que se creían superados, la actuación de lo massmediático audiovisual resultó una experiencia casi inédita de impudicia, obscenidad ideológica y carente de toda "objetividad" en cuanto a la política de imagen y de los encuadres por parte de los canales y sus noticieros. (conf., Nicolás Casullo, Página 12, 30 de marzo de 2008).

Ese periodismo forma parte del enorme ejército de intelectuales orgánicos de los sectores dominantes cuya estratégica misión es construir e inculcar en nuestras sociedades una versión falsa de la historia y de la realidad actual. En otras palabras, fabricar el clima ideológico requerido para favorecer la emergencia de fuerzas políticas conservadoras aptas para capturar el apoyo de una ciudadanía meticulosamente desinformada por los medios de comunicación que controla el gran capital y preservar la hegemonía de los intereses del imperialismo y sus clases aliadas en la periferia (conf., Atilio Borón, Página 12, del 30.03.2008).

En el fondo el tema es político. Los verdaderos pequeños $y$ medianos productores no fueron

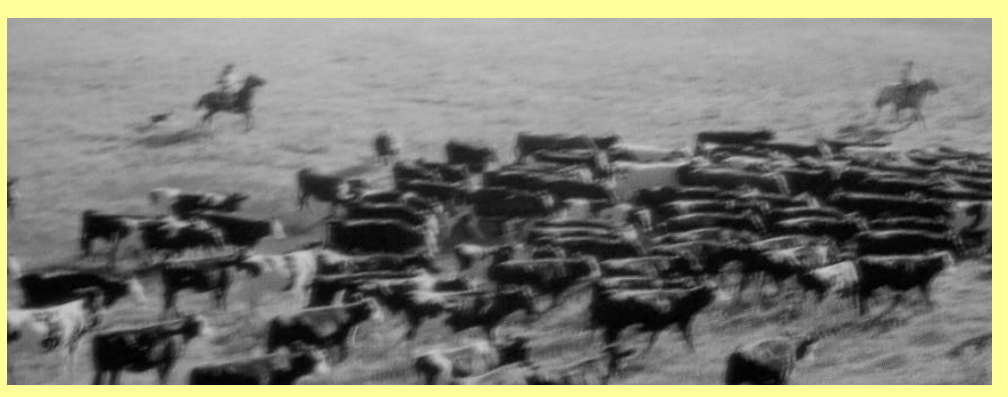
ni serán postergados. Ante esa protesta, cuánto pueden decir millones de argentinos que sólo cuentan con su fuerza de trabajo y que recién están saliendo de la desocupación y la "flexibilidad laboral" con pérdida de derechos que le impuso el esquema "neoliberal". Es imprescindible acompañar y defender las políticas de Estado que se adoptaron, como asimismo otras que seguramente se adoptarán para superar

\section{la situación imperante y proseguir la marcha hacia un país soberano y digno.}

Se deben transmitir y hacer conocer los fundamentos que las impulsan, en un debate que no debemos tener temor a enfrentar. Sólo así, a través del pleno conocimiento de sus motivos podrá lograrse una acción conciente de los distintos sectores sociales, que son quienes finalmente las habrán de apoyar y sostener. 
Las diversas campañas que se están ejecutando para torcer el camino iniciado, sólo son actitudes recientes de la vieja táctica de esos sectores dominantes, que la oligarquía usó y sigue usando en forma solapada. Cuando saben que peligran sus intereses, intentan o pretenden confundir para que no hagan mella a su poder real. Su trama tiene estos tiempos: primero disuaden con la astucia y luego someten por la violencia, institucionalizada o no. El golpe de Estado y el terrorismo que desde alli aplicó es su último recurso. Por ello es imprescindible recordarlo y confrontar políticas. Hay que cerrar el paso al agro-golpismo. Hacer llegar al Pueblo las razones que impulsan las políticas del gobierno es el arma más potente que existe para vencer esa trama siniestra y enfrentar a los sectores que se oponen al cambio social en la Argentina.

\section{Otra publicación sobre el tema:}

"En el Centenario del Grito de Alcorta", Realidad Económica, Revista de Economía editada por el Instituto Argentino para el Desarrollo Económico - IADE, N² 268, 27 de julio de 2012. 